\title{
Premio "RCE Award for Outstanding Flagship Project" de la Universidad de las Naciones Unidas para el Diplomado en Biodiversidad y Saberes Interculturales
}

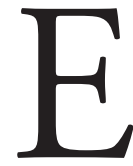

n noviembre de 2014, Japón fue sede de un importante evento mundial organizado por UNESCO en Educación para el Desarrollo Sostenible (EDS). Se trataba del IX Congreso de Centros de Experticia en Educación para el Desarrollo Sostenible (RCE) en Okayama, que contó con la participación de la Mg. Teresa Salinas, directora ejecutiva del RCE Lima-Callao, quien presentó el trabajo The raising in life: Una experiencia formativa en los andes centrales del Perú, el cual está basado en el Diplomado en Biodiversidad y Saberes Interculturales que logró en este congreso el Premio RCE Recognition Award por Outstanding Flagship Project (Proyecto Bandera Sobresaliente), otorgado por la Universidad de las Naciones Unidas.

El Diplomado en Biodiversidad y Saberes Interculturales fue impulsado por el Programa de Desarrollo Rural Sostenible (PDRS) de la GIZ con el apoyo de un grupo de destacados estudiosos y conocedores de la región San Martín. Además, se insertó en los procesos formativos y de investigación del Instituto Peruano del Pensamiento Complejo (IPCEM) de la Universidad Ricardo Palma (URP) y el Centro Regional de Competencias sobre Educación para el Desarrollo Sostenible, RCE Lima-Callao.

Este proyecto contó con el apoyo y financiamiento de la Agencia Alemana de Cooperación Internacional (GIZ), el Programa de las Naciones Unidas para el Medioambiente (PNUMA) y la Universidad Ricardo Palma. Los módulos presenciales se desa-

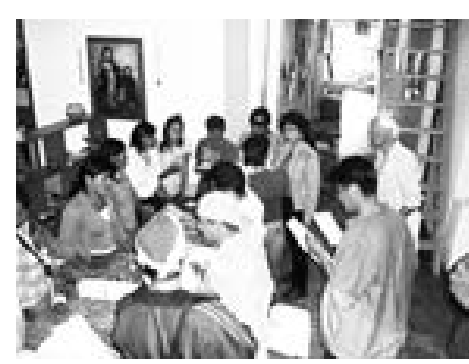

Imagen 2: Desarrollo de clases del Diplomado.

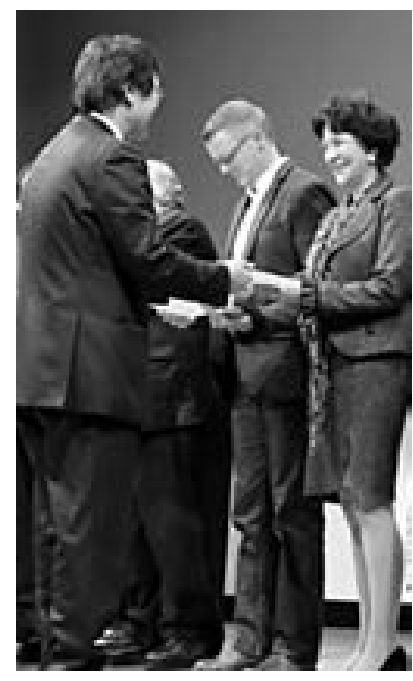

Imagen 1: Premio RCE

Recognition Award por

Oustanding Flagship Project al Diplomado en Biodiversidady Saberes Interculturales otorgado por la Universidad de las Naciones Unidas (UNU). En la foto, la Prof. Teresa Salinas Gamero recibe el premio de manos del Dr. Kazuiko Takemoto, director del Instituto de Estudios Avanzados de Sostenibilidad de la UNU. enfoque innovador del pr yecto para la revitalización de las culturas tradicionales y la promoción de la evolución que lleva en conjunto a la modernidad. Asimismo, aborda, desde un enfoque complejo y transdisciplinar, la interculturalidad, la religación local-global y el acercamiento del trabajo de la Universidad Ricardo Palma con los agentes sociales y las comunidades nativas del país. 
Acerca del diplomado, el PNUMA destacó que era "novedoso y único en la región de América Latina, ya que ofrece un espacio de reflexión, debate y formación académica basado en la experiencia y la documentación existentes de la región San Martín para estimular la sistematización y difusión de las prácticas y los saberes ancestrales en el marco del diálogo de saberes para beneficio del conjunto de la región andino amazónica y del país" (Convenio URP-PNUMA).

El 16 de abril del 2015, en el centro cultural Ccori Wasi, la Universidad Ricardo Palma entregó placas y certificados de reconocimiento a las organizaciones y personas que contribuyeron al Diplomado en Biodiversidad y Saberes Interculturales. Con el mismo objetivo, se reconoció el trabajo de los alumnos más destacados del diplomado, quienes pertenecen a la comunidad Kewcha de Morillo.

Este premio a nivel mundial, concedido por la Universidad de las Naciones Unidas a la Universidad Ricardo Palma, nos compromete a seguir desplegando esfuerzos en la recuperación de los saberes interculturales y en la construcción de una sociedad más justa y sostenible.

El IPCEM es un centro de investigación de la URP dedicado al estudio de la complejidad y transdiciplinariedad. El Centro Regional de Competencias sobre Educación para el Desarrollo Sostenible, RCE Lima-Callao, está compuesto por un conglomerado de organizaciones públicas y de la sociedad civil que busca promocionar ese tipo de educación. El coordinador del centro es la URP, vía el IPCEM. El RCE LimaCallao ha sido reconocido, desde el 2011, por la Universidad de las Naciones Unidas y forma parte del movimiento mundial

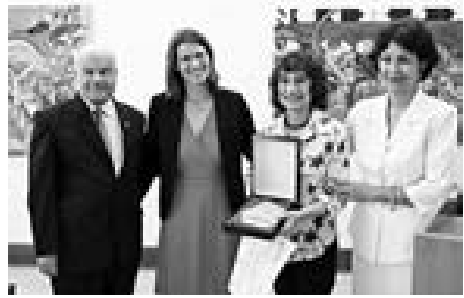

Imagen 3: El Dr. Iván Rodríguez, rector de la URP, la Dra. Silke Sphon, directora del Programa Proambiente de la Deutsche Gesellschaft für Internationale Zusammenarbeit (GIZ) GmbH y la Prof. Teresa Salinas Gamero entregan una placa de reconocimiento a la Dra. Eloiza Tréllez, representante de GIZ en el Diplomado.

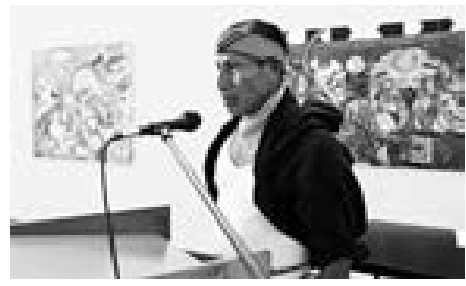

Imagen 4: Palabras de Misael Salas, alumno destacado del diplomado y miembro de la comunidad Kewchua Lamas de Morillo. de los RCE que promocionan el Plan de Acción Global (Global Action Plan, GAP) de UNESCO. Mayores informes en www.urp.edu.pe/ipcem y www.rcelimacallao.org 